\title{
Infantail Kawasaki with Coronary Arteries Aneurysm
}

\author{
Mahmoud Al Soufi ${ }^{1 *}$ and Samah Asrawi ${ }^{2}$ \\ ${ }^{1}$ Consultant Pediatric Cardiologist, AlJalila Children Heart Center, UAE
}

${ }^{2}$ Specialist Pediatric Cardiologist, AlJalila Children Heart Center, UAE

Submission: November 30, 2017; Published: December 19, 2017

*Corresponding author: Mahmoud Al Soufi, Specialist Pediatric Cardiologist, AlJalila Children Heart center, Dubai, UAE, Email: dr.m.soufi@hotmail.com

\section{Introduction}

Kawasaki disease is an acute vasculitis of childhood that predominantly affects the coronary arteries [1-3]. The etiology of Kawasaki disease remains unknown [4], although an infectious agent is strongly suspected based on clinical and epidemiologic features $[5,6]$. Most children who are treated recover from the disease without long-term problems [1,5]. Other need close follow up and special treatment by Aspirin, IVIG and sometimes Steroids [7-9]. The disease is most common in children ages 1 to 2 years $[2,4]$ and is less common in children older than age 8 or in infants [10]. We are presenting 4 months old girl with Kawasaki disease complicated with coronary arteries ectasia and aneurysm which is unusual in this age.

\section{Case Report}

4 months old girl presented to emergency department with fever not responding to oral Antipyretic for 14 days, with red eyes and red lips and mild trunk rash from 4 days before the admission mild lethargy, and irritability [11].

\section{On examination}

Irritable child Scattered on face and red eyes, peeling of fingers and toes. No peripheral edema, red lips.

Other systemic examination was normal.

CRP was high 70, WBC $=17200, \mathrm{Hgb}=7.2 \mathrm{~g} / \mathrm{dl}$, Htc $=26 \%$, PLT $=715000$, Albumin $=4.3 \mathrm{mg} / \mathrm{dl}$, virology: RSV and influenza negative.

ECG: Normal sius rhythm, No ischmic changes (Figure 1).

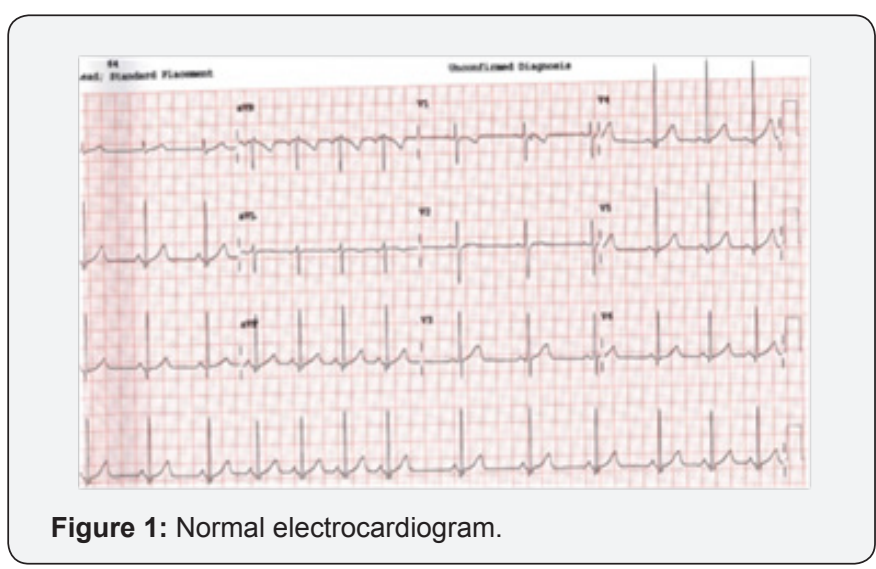

Figure 1: Normal electrocardiogram.
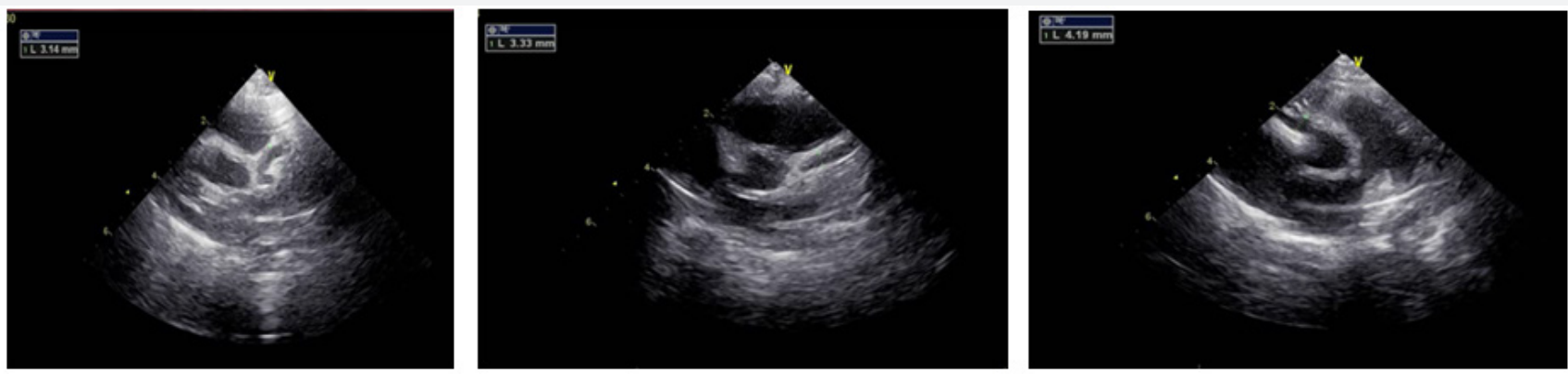

Figure 2

Echo cardiograph showed Dilated both coronary arteries with ectasia along the course of both coronary LCA 3.3-3.6mm, LAD $3 \mathrm{~mm}$. aneurismal formation measuring $4.19 \mathrm{~mm}$ at the origin of RCA (Figure 2).
Patient was received high dose I.V.I.G $(2 \mathrm{gm} / \mathrm{Kg})$ over $24 \mathrm{~h}$ associated with anti-inflammatory dose of Aspirin $75 \mathrm{mg} / \mathrm{Kg} /$ day. After 24 hours, she showed some clinical improvement, low grade fever, no irritability and better appetite so that we continue her on 
same treatment plan under close observation. After 1 week she improved dramatically with no complain and stable vital signs [12].

LAB: $C R P=9.9$. Echocardiography showed same finding and measures (dilated booth coronary arteries with ectasia along the course of both coronary LCA $3.3-3.6 \mathrm{~mm}$, LAD $3 \mathrm{~mm}$. Aneurysmal formation measuring $4 \mathrm{~mm}$ at the origin of RCA.

Patient was discharged home in very good condition and stable vital signs on anti platelate Aspirin dose (3-5mg/Kg/day) and given appointment in our clinic for follow up [13].

\section{After 1 month}

She was in very good condition, No complain, happy and active child.
LAB: $\quad$ CRP $<5$. Echocardiography showed: Same finding and measures ectasia along the course of both coronary with aneurysmal formation. She was kept on Aspirin low dose and under follow up as outpatient in our clinic.

\section{After 3 months}

Also remain stable, no complain, gaining weight and feeding well. Normal physical examination.

Her echo findings showed: Both coronary arteries looks smaller than before with ectasia along the course of both coronary LCA $2.2 \mathrm{~mm}$, LAD $2.6 \mathrm{~mm}$ [14]. Small aneurismal formation measuring $2.9 \mathrm{~mm}$ at the origin of RCA distal RCA is normal $2 \mathrm{~mm}$ (Figure 3)
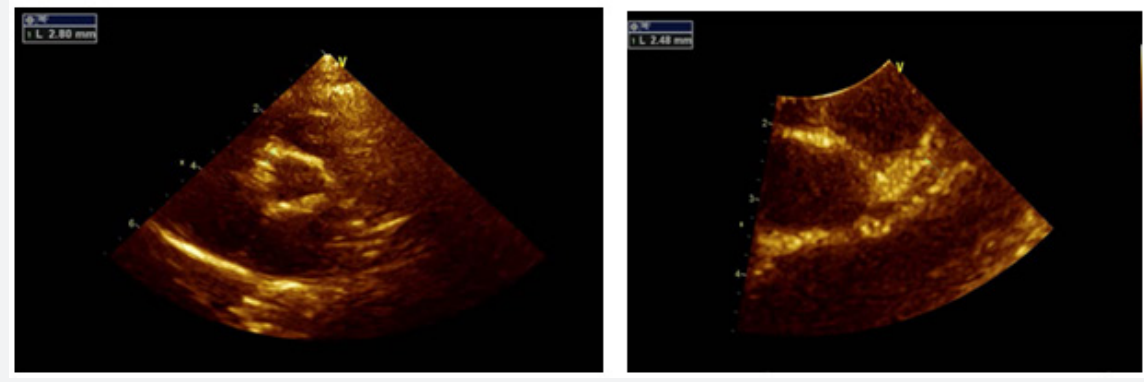

Figure 3: Smaller ectasia and smaller aneurysm.
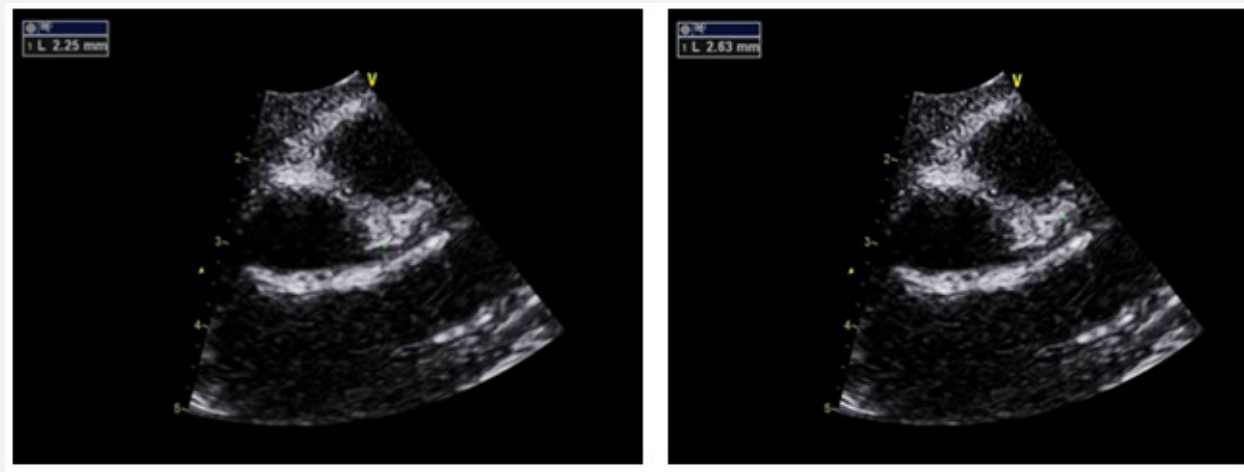

Figure 4: Echocardiography after 6 months.

After 6 months the Echo showed mild ectasia along the course of both coronaries, LCA at the origin $2.9 \mathrm{~mm}$ and LAD $2.2 \mathrm{~mm}$. Small aneurysmal formation measuring $2.8 \mathrm{~mm}$ at the origin of RCA (Figure 4).

\section{Discussion}

In spite of Kawasaki is uncommon autoimmune disease with self limited course history [15], however its complication are still serious and should be considered and evaluated carefully to prevent a serious and life threatening events [9].
The causes of Kawasaki disease remain unknown [3], but $\mathrm{A}$ genetic predisposition is also likely, based on varying incidences among ethnic groups, with higher rates in Asians [12]. Symptoms include fever, conjunctival injection, erythema of the lips and oral mucosa, rash, and cervical lymphadenopathy. Some children with Kawasaki disease develop coronary artery aneurysms or ectasia, ischemic heart disease, and sudden death. Kawasaki disease is the leading cause of acquired heart disease among children in developed countries [5,7]. 
Our case was a rare Kawasaki case because the age $<1$ year, and that was one of the risk factors for predicting aneurysms in addition to:
A. White blood cell count $>12000 / \mathrm{mm}^{3}$
B. $\quad \mathrm{CRP}>3+$
C. Hematocrit $<35 \%$
D. Albumin $<3.5 \mathrm{~g} / \mathrm{dL}$

E. Age $\leq 12$ months; and the others risk factors (male sex; platelet count $<350000 / \mathrm{mm} 3$ ) not in this case.

Although all these risk factors the case treated and responded well to IVIG $2 \mathrm{gm} / \mathrm{kg}$, and high dose of Aspirin $75 \mathrm{mg} / \mathrm{kg} /$ day then continued in the anticoagulant dose $5 \mathrm{mg} / \mathrm{kg} /$ day. Some refractory cases of Kawasaki disease require special and unusual treatment like repeated doses of IVIG, steroid, Plasma electrophoresis, anti TNF (anflaximab).

Kawasaki is a clinical diagnosis according to clinical manifestations supported by some positive laboratory test, but there is no specific laboratory test to confirm Kawasaki disease. Echocardiography by expert hands focusing on coronary arteries is essential to confirm the diagnosis and detect the cardiac findings early and also in follow up plan for any patient with Kawasaki or suspected Kawasaki disease.

\section{References}

1. Newburger JW, Takahashi M, Burns JC, Beiser AS, Chung KJ, et al. (1986) The treatment of Kawasaki syndrome with intravenous gamma globulin. N Engl J Med 315(6): 341-347.

2. Kusakawa S (1983) Kawasaki disease: results of study by a research group of the Ministry of Health and Welfare. Nihon Rinsho 41: 19701977.

3. Manlhiot C, Millar K, Golding F, McCrindle BW (2010) Improved classification of coronary artery abnormalities based only on coronary artery z-scores after Kawasaki disease. Pediatr Cardiol 31(2): 242-249.
4. Tsuda E, Hamaoka K, Suzuki H, Sakazaki H, Murakami Y, et al. (2014) A survey of the 3-decade outcome for patients with giant aneurysms caused by Kawasaki disease. Am Heart J 167 (2): 249-258.

5. Levy DM, Silverman ED, Massicotte MP, McCrindle BW, Yeung RS (2005) Longterm outcomes in patients with giant aneurysms secondary to Kawasaki disease. J Rheumatol 32(5): 928-934.

6. DeZorzi A, Colan SD, Gauvreau K, Baker AL, Sundel RP, et al. (1998) Coronary artery dimensions may be misclassified as normal in Kawasaki disease. J Pediatr 133(2): 254-258.

7. Dajani AS, Taubert KA, Gerber MA, Shulman ST, Ferrieri P, et al. (1993) Diagnosis and therapy of Kawasaki disease in children. Circulation 87(5): 1776-1780.

8. Umezawa T, Saji T, Matsuo N, Odagiri K (1989) Chest $\mathrm{x}$-ray findings in the acute phase of Kawasaki disease. Pediatr Radiol 20(1-2): 48-51.

9. Holve TJ, Patel A, Chau Q, Marks AR, Meadows A, et al. (2014) Longterm cardiovascular outcomes in survivors of Kawasaki disease. Pediatrics 133: e305-e311.

10. Suda K, Iemura M, Nishiono H, Teramachi Y, Koteda Y, et al. (2011) Long-term prognosis of patients with Kawasaki disease complicated by giant coronary aneurysms: a single-institution experience. Circulation 123(17): 1836-1842.

11. Levy DM, Silverman ED, Massicotte MP, McCrindle BW, Yeung RS (2005) Long term outcomes in patients with giant aneurysms secondary to Kawasaki disease. J Rheumatol 32(5): 928-934.

12. Takahashi M, Mason W, Lewis AB (1987) Regression of coronary aneurysms in patients with Kawasaki syndrome. Circulation 75: 387394.

13. deZorzi A, Colan SD, Gauvreau K, Baker AL, Sundel RP, et al. (1998) Coronary artery dimensions may be misclassified as normal in Kawasaki disease. J Pediatr 133: 254-258.

14. Newburger JW, Takahashi M, Gerber MA, Gewitz MH, Tani LY, et al. (2004) Diagnosis, treatment, and long-term management of Kawasaki disease: a statement for health professionals from the Committee on Rheumatic Fever, Endocarditis, and Kawasaki Disease, Council on Cardiovascular Disease in the Young, American Heart Association. Circulation 110(17): 2747-2771.

15. Stamos JK, Corydon K, Donaldson J, Shulman ST (1994) Lymphadenitis as the dominant manifestation of Kawasaki disease. Pediatrics 93(3): 525-528.

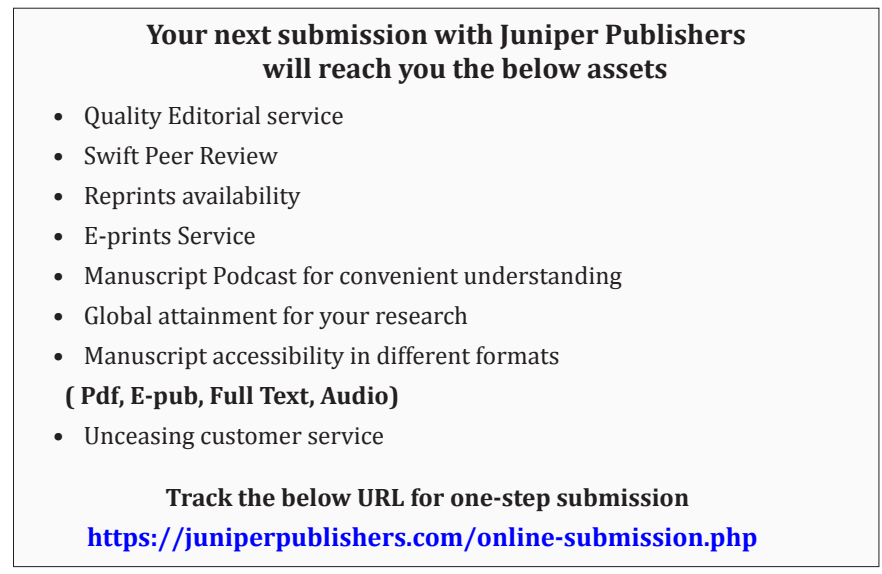

